\title{
In retrospect chosen by John L. Casti
}

\section{Gödel, Escher, Bach: An Eternal \\ Golden Braid}

by Douglas Hofstadter

(1979)

A classic dinner-party game I like to play is to ask my guests what science book published, say, during the past 25 years they would take if they were to be stranded indefinitely on a desert island. For me the choice is easy: I would grab a copy of Douglas Hofstadter's Gödel, Escher, Bach (GEB) before abandoning ship.

Alternating witty, enlightening dialogues with chapters on such meaty topics as selfreference, recursion, meaning in mathematics, formal systems of logic, brains, the weird and wonderful art of M. C. Escher, minds, thoughts, typesetting, Gödelian paradoxes, selfreplication, artificial intelligence and hierarchies, GEB is more like a summary statement of most of modern cognitive science than a thematic book, more of a romp over the modern intellectual landscape than a scholarly monograph. Yet it manages to be all these things and more.

At the time $G E B$ was sitting on bestseller lists around the world, a lot of people joked that it was a book everyone bought and no one read. Well, not me. I have a friend who says that each Christmas he rereads every Sherlock Holmes story because he learns something new with each rereading. I don't want to claim that I've now reread GEB 17 times, but I have read it cover-to-cover several times - and always with great profit. One reading taught me things about Bach fugues that I had never properly

own right, is very drastic, and Cao does not explain how a mechanical ontology can emerge from field physics as an epiphenomenon. Perhaps we just have to accept an ontological enlargement.

The situation is much worse, I believe, in the case of quantum field theory. Superficially, quantum field theory sounds like a synthesis of quantum mechanics and classical field theory. But this immediately leads to a problem. The quanta of force fields are bosons, yet the theory must also include fermions, for which there is no classical field. As Cao explains, this led historically to the procedure called "second quantization", which seems to be associated with a particle rather than a field ontology. But either ontology (particle or field) is problematic, because bosonic and fermionic quantum fields are quantum operators whose matrix elements are quantities from which only probabilities can be calculated, as is typical in quantum mechanics.

Cao claims that physicists have still not clarified the "real material" versus "probabilistic" character of the quantum field. He himself regards it as a new kind of substantial field, and with this view it is easier to find the kind of ontological continuity he wants. For appreciated, another time I gained a deeper insight into the figure-ground distinction, while a third reading heightened my sensitivities to the connection between Gödel's “incompleteness theorem”, self-reference and Escher's famous engraving Ascending and Descending. All these intellectual gleanings are secondary matters to the book's main theme, which is an extended meditation on the possibility of duplicating human thought processes in a machine.

I don't think it would be too great a claim to date the birth of the 'connectionism' movement in artificial-intelligence research to the publication of GEB in early 1979. This is the view that the physical structure of the human brain matters when it comes to trying to duplicate in a computing machine what the brain does.

Before then, workers had spent the better part of 30 years trying to skim off human intelligence from the actual physiological structure of the brain, essentially ignoring things like behaviour and connective structures at the level of the brain's neurons. Hofstadter redirected attention to these lower-level structures, arguing that if one wants to capture human cognition in a mechanical intelligence, the machine must mirror these low-level features of the brain. $G E B$ 's presence on the bestseller lists for months, along with its winning the 1980 Pulitzer prize for general nonfiction, brought this connectionist view of machine intelligence back to the forefront of research in artificial intelligence. Thus were reborn the theories of neural networks, genetic

example, he "can claim without hesitation that the gauge field programme is a direct descendant of the geometrical programme".

In fact, quantum field theory is really the result of trying to reconcile quantum mechanics with special relativity. Its ontology is no different from that of quantum mechanicsitself — and here we hit a barrier. Ontology, Cao says, is "concerned with an autonomous existence without reference to anything external". But, according to what is still the standard (Bohrian) view, although the existence of some independent microscopic reality behind observed phenomena is accepted, questions about the nature or state of that reality have meaning only in the context of explicitly stated external experimental setups. In some way, attributes and quantities even entities themselves - are ceaselessly fluctuating at the quantum level, and become real only as a result of 'measurement'. The simple connection between observed properties and ontological properties of an independently existing object has been severed. Of course, other interpretations have been proposed such as the 'many worlds' one; but this example has rather too much ontological baggage for many people's taste. algorithms, evolutionary programming and all the other 'hot' theories in the field.

It is interesting to ponder what makes $G E B$ a book many purchasers have never read, while it has changed other folk's view of the world like mine. On the downside, the book is a real doorstop, 778 pages long and more than two pounds in weight. So it's a bit of a package for comfortable reading on the subway or the beach. Some people have complained that it is rather disjointed and rambling, moving from topic to topic and back again with no apparent beginning or end. While I have to admit that there is some truth to these allegations, one might register the same complaints about the Encyclopedia Britannica. GEB cannot be measured by the standards usually employed to evaluate books. It's a one-of-a-kind volume that has to be looked at in its own right, which to their eternal credit the Pulitzer committee members immediately recognized.

On the asset side of the ledger, GEB is the best example I know of a 'transdisciplinary' book. Laying out explicit linkages between the humanities, art, science and mathematics, it proves that the landscape of the intellect does not come conveniently packaged into compartments such as English, physics, computer science and psychology. In some ways, GEB is an entire humanistic education between the covers of a single book. So, for my next visit to a desert island, give me sun, sand, water and $G E B$, and I'll live happily ever after.

John L.Casti is at the Santa Fe Institute, Santa Fe, New Mexico 87501, USA.

Perhaps Cao should have avoided the 'substantial' aspect of ontology, and stuck to the 'structural' aspects he himself advocates: witness, for example, the mathematical survival of Maxwell's equations. But, even at this level, the significance of the mathematical similarity between the space-time geometry of general relativity and 'internal' symmetries of gauge field theory is unclear.

Despite their having been invented in the same century, there is still a great divide between general relativity and quantum field theory. Perhaps the difficulty of reconciling them is an indication that our current ontological categories are inadequate, and that Cao's bold attempt at ontological synthesis is simply premature.

Ian Aitchison is in the Department of Physics, University of Oxford, 1 Keble Road, Oxford OX1 3NP, UK.

\section{correction}

The title of the book by Harrison G. Pope Jr reviewed by Stuart Sutherland in last week's issue (Nature 388, 239; 1997) was given incorrectly. It is Psychology Astray: Fallacies in Studies of 'Repressed Memory' and Childhood Trauma. 


\section{Tales of memory and imagination}

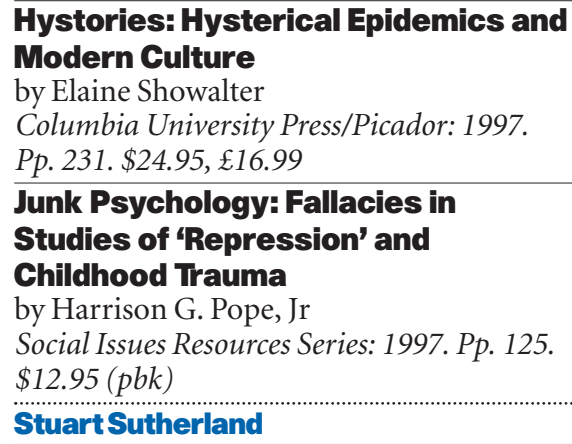

Everyone loves stories or, as Elaine Showalter rather portentiously calls them, "narratives". In Hystories - which might more appropriately, as she half admits, be entitled Herstories - she examines the tales developed by hysterics in both literature and real life.

She uses the term "hysteria" in the layman's sense to refer broadly to any hyperemotional state accompanied by histrionic and attention-seeking behaviour. One of her rasher suggestions is that the British reaction to "mad-cow disease" was caused by the British fear of madness, a bizarre speculation given that the consumption of beef at one time declined more in Germany than in Britain.

Her review of the portrayal of hysteria in literature is not without interest, although her belief that it began with Flaubert's Madame Bovary and the Victorian romantics is odd. Perhaps she should try rereading Euripides' Bacchae.

Although she is a professor of English literature, her account of recent epidemics of hysteria in the United States is perhaps more worthwhile: although slight, it pulls together the different outbreaks, but the recent torrent of books on this subject makes it impossible to say anything new.

She deals with the syndromes of recovered memory, multiple personality, satanic ritual abuse and alien abduction, and courageously includes Gulf War and chronic fatigue syndromes as examples of hysteria: not only is it just possible that a pathogenic agent will be found in both illnesses, but the sufferers desperately want the cause to be organic, presumably to avoid the stigma of mental illness.

Like Freud, she concentrates on case histories rather than a scientific approach. She rightly stresses that people develop these syndromes partly as an excuse for and an explanation of their own failings and sometimes to escape punishment. Some have pleaded that they committed murder or rape as a different personality, and at least one person has pleaded in court that he had been forced to commit a crime by aliens.

Indeed, the most interesting aspect of these "hysterias" is their causes, many of which Showalter does not mention. They include: the desire for attention; the comfort of being able to abdicate responsibility for one's failings by ascribing them to an illness; the luxury of receiving therapy (compounded in the case of multiple personality by the fact that in the United States therapy can now be obtained under health insurance thanks to its recognition as a disorder by the American Psychiatric Association); the excitement added to a humdrum life by weird beliefs about one's past; the propagation of hysterics' stories by the mass media; and the attempts by therapists to push their clients into revealing multiple personalities, non-existent sexual abuse, and even alien abduction in the mistaken belief that such revelation will effect a cure.

Finally, there may be a monetary pay-off for hysteria: although nobody has yet sued an alien abductor, people have obtained compensation from their fathers for abuse and others are busy suing the American military for the Gulf War syndrome. In a wry twist, patients are now prosecuting their therapists for breaking up their lives by instilling fictitious beliefs.

Showalter suggests that one cause of these hysterias is to give vent to repressed desires in concealed form. Women feel frustration for the sexual acts they have not performed and guilt for those they have. There is no suggestion that male hysteria, which is comparatively rare, is caused by sexual problems although in this age men have plenty of those. She displays an uncritical acceptance of Freudian beliefs and ways of thought, an act of faith now virtually confined to novelists and literary critics, both professions more interested in a good 'narrative' than the truth.

The approach of Harrison Pope, a psychiatrist, could hardly be more different. $\mathrm{He}$ eschews all case histories on the grounds that they are biased by both the therapist's and the patient's ability to deceive themselves.

In evaluating whether there exist repressed but recoverable memories of traumatic events, Pope points out that in every study where survivors of a traumatic event, such as a collision between ships or the kidnapping of a school bus, have been interviewed several years later, all participants have had excellent recall — no sign of repression there.

He meticulously destroys the findings of a study by L. M. Williams which is the one most cited by believers in repressed memory: she interviewed 129 people who had been evaluated in hospital for signs of sexual abuse. Of these women, 49 claimed to have forgotten the abuse.

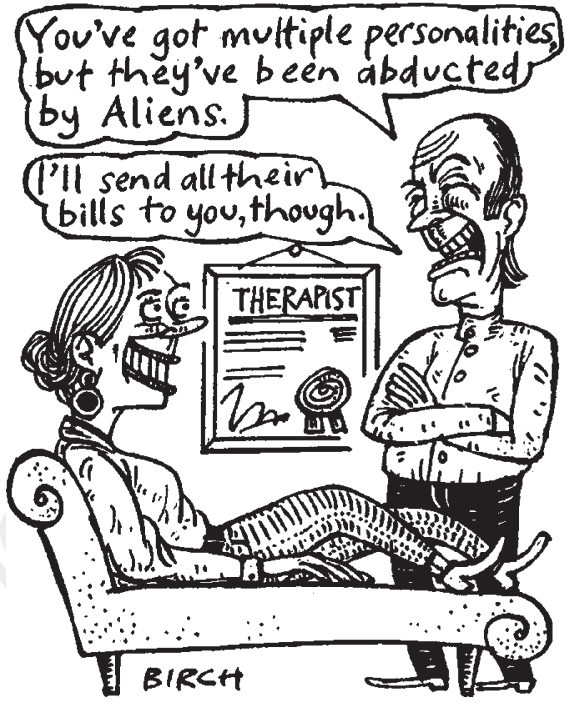

Using known facts on the reporting of abuse, Pope is able to show convincingly that their forgetting can readily be accounted for - at the time of the abuse some were under the age when memories can be formed; others had not been sexually abused at all according to the hospital's investigation; and a few did not want to disclose the abuse, a tendency well documented in other studies.

There is no need to invoke repression as the cause of forgetting: indeed there is no evidence for the existence of repression. Pope also demonstrates that the belief that sexual abuse propagates from one generation to the next is equally groundless.

Junk Psychology is a model of clear thinking and clear exposition. It outlines the pitfalls of epidemiology such as confounding causes: post hoc does not mean propter hoctwo correlated events may have a common cause, such as genetic factors.

To clarify his argument he analyses widely held but mistaken popular and medical myths: for example that salt is bad for you, that power lines damage the body, and that schizophrenia is caused by bad upbringing. Pope's careful analysis of possible sources of error should be useful to intending epidemiologists, and regrettably some practising ones, and to other disciplines within the social sciences.

A comparison of the two texts shows that, as is usually the case, the prose style and clarity of the scientist are far superior to those of the professor of English. In this postmodernist world, literary criticism might well fare better if it were taken over by scientists. But God help science if literary critics reciprocated this gesture.

Stuart Sutherland is at the Laboratory of

Experimental Psychology, University of Sussex, Falmer, Brighton BN1 9QG, UK. 